\title{
Paisajes culturales de la Antigüedad en los valles del Tormes y del Corneja (Ávila)
}

\author{
Ancient Cultural Landscapes in the Valleys of Tormes and Corneja \\ (Ávila)
}

\author{
JOSÉ MIGUEL HERNÁNDEZ SOUSA \\ Universidad Autónoma de Madrid \\ josemiguel.hernandez@predoc.uam.es
}

Resumen: El presentetrabajo pretende ofreceruna visión diacrónica de la antigua ocupación humana en los valles del Tormes y del Corneja (Ávila), abarcando cronológicamente los momentos culturales incluidos entre la II Edad del Hierro y la Alta Edad Media (ss. II a. C. x d. C.). La información sobre los yacimientos procede tanto de prospecciones sistemáticas extensivas e intensivas, así como de algunas excavaciones arqueológicas. Se presenta así por primera vez un análisis de conjunto, diacrónico y comparativo, del poblamiento antiguo en esta zona serrana y de las dinámicas que marcaron su transformación durante la época romana y tardoantigua. Mediante el recurso a las Técnicas de Información Geográfica (TIG), se ha recopilado e incluido toda la información arqueológica relativa a los yacimientos documentados en esta zona, analizándola de forma combinada junto con aquella relativa a su contexto espacial (vías de comunicación, toponimia, recursos naturales, medio físico, etc.). Todo ello nos permite, por un lado, trazar la evolución del poblamiento en este territorio, ofreciendo una visión de largo alcance y, por otro, insertar este sector serrano en los procesos que definen este periodo en otras áreas próximas, en especial, en las vecinas tierras salmantinas y madrileñas.

Palabras clave: poblamiento rural, valle del Tormes, Aravalle, Corneja, Ávila

Abstract: This paper offers a diachronic interpretation of the ancient human occupation
of the Tormes and Corneja valleys (Ávila), chronologically including the cultural times
between the II Iron Age to the High Middle Ages ( $2^{\text {nd }}$ century BC $-10^{\text {th }}$ century AD). The
information on the deposits comes from extensive and intensive systematic surveys as
well as some archaeological excavations. For the first time it is presented a diachronic
and comparative analysis of the old settlement in this mountain area and of the dynamics
that marked its transformation during the Roman period and Late Antiquity. By using
Geographic Information Techniques (GIS), all the archaeological information related to
the sites documented in this area has been compiled and analyzed together with that
relating to its spatial context (ways of communication, toponymy, natural resources,

Recibido: 2 de enero de 2018; aceptado: 10 de agosto de 2018; publicado: 30 de marzo de 2019.

Revista Historia Autónoma, 14 (2019), pp. 11-35

DOI: https://doi.org/10.15366/rha2019.14.001 
physical environment, etc.). All this allows us to, on the one hand, trace the evolution of the settlement in this territory, offering a vision of long reach and, on the other hand, insert this sector serrano in the processes that define this period in other nearby areas, especially in the neighboring lands in Salamanca and Madrid.

Keywords: Rural settlement, Tormes valley, Aravalle, Corneja, Ávila.

\section{Introducción}

A lo largo de los últimos años, el estudio del territorio ha conocido un desarrollo tan destacado que ha accedido al estatus de disciplina propia. Este tipo de estudios han demostrado ser fundamentales para el análisis y comprensión de las sociedades que lo habitaron y transformaron, pese a la gran heterogeneidad de objetivos y métodos empleados ${ }^{1}$.

Todo estudio sobre un territorio analiza un paisaje compuesto por una sucesión de elementos de diferente cronología; un conjunto complejo y en constante evolución ${ }^{2}$, un palimpsesto. La investigación debe estudiar el origen y evolución de cada uno de estos elementos, cuyo análisis permitirá comprender cada una de las fases que en las que se ha conformado el territorio ${ }^{3}$. Un estudio arqueológico así planteado no puede ignorar que el paisaje es el resultado de una sociedad, con sus propios modos de entenderlo, concebirlo y transformarlo ${ }^{4}$.

La zona de trabajo elegida se localiza en la ladera septentrional del Sistema Central, más concretamente en la zona en la que interrelacionan los valles del alto Tormes y sus afluentes -Aravalle y otros- y del Corneja, situados en la provincia de Ávila, con una superficie de 1441 $\mathrm{km}^{2}$. Es un espacio que aúna la alta montaña con la transición hacia el dominio sedimentario del centro de la cuenca del Duero. En esta zona, han sido tradicionales los usos ganaderos, en estrecha relación con los agrícolas y gestión del bosque, adaptando los usos del suelo a

\footnotetext{
${ }^{1}$ Orejas Saco de Valle, Almudena, "Arqueología del paisaje: historia, problemas y perspectivas", en Archivo Español de Arqueología, 64 (1991), p. 191.

${ }^{2}$ Grau Mira, Ignasi et al., "Propuestas metodológicas para el estudio del paisaje rural antiguo en el área central de La Contestania", en Zephyrus, 70 (2012), pp. 131-149; Orejas Saco del Valle, Almudena, "Arqueología del paisaje: de la reflexión a la planificación", en Archivo Español de Arqueología, 68 (1995), pp. 215-224. Francovich, Riccardo y Richard Hodges, Villa to village. The tansformation of the Roman Countryside in Italy, c. 400-1000, Londres, Oxbow Books, 2003.

${ }^{3}$ Hernández Sousa, José Miguel, “Arqueología del Paisaje (estudio del territorio) en el curso alto del río Manzanares. El poblamiento romano, tardoantiguo y altomedieval", en Másteres de la UAM 2013-2014, Universidad Autónoma de Madrid, 2015, p. 6.

${ }^{4}$ Ariño Gil, Enrique et al., El pasado presente. Arqueología de los paisajes en la Hispania romana, Barcelona y Salamanca, Universitat de Barcelona y Universidad de Salamanca, 2004, p. 13.
} 
los cambios sociales y estacionales del paisaje ${ }^{5}$. Se trata de aprovechamientos tradicionales ${ }^{6}$, escalonados altitudinalmente entre los rebordes montañosos y el fondo de valle ${ }^{7}$.

El presente estudio se basa en el examen de un total de 27 yacimientos con una cronología entre la II Edad del Hierro y la Alta Edad Media. Hemos adoptado una perspectiva diacrónica y multidisciplinar, mediante la que tratamos de reunir el heterogéneo y desigual registro material generado por las sociedades de la antigüedad. Es este un período donde las formas del poblamiento, la ocupación del territorio y las estrategias de explotación del medio son temas de actualidad ${ }^{8}$.

\section{El medio natural}

La comarca del valle del Tormes y Corneja se encuentra al sudoeste de la provincia de Ávila. Queda delimitada al noreste por las estribaciones más occidentales de la sierra de Ávila y la sierra de Villanueva; por la parte meridional por la de Gredos; por el este por La Serrota; mientras al oeste es la sierra de Béjar la que delimita su territorio. La altitud general oscila entre los $1000 \mathrm{~m}$ en los valles y de 1500- $2600 \mathrm{~m}$ en las sierras.

Los bordes S y O de la cuenca sedimentaria del Duero ${ }^{9}$, correspondiente al alto Gredos y la sierra de Béjar, comprende el conjunto más abrupto y elevado de la provincia abulense. Las sierras de Villafranca, La Serrota y Ávila, son un conjunto en gran parte paralelo, a la barrera montañosa de Gredos, aunque de menor altitud y con una disposición más septentrional. La situación de la sierra de Gredos hace que sea la divisoria entre las aguas de la cuenca del Duero y Tajo, pese a que el Alberche, afluente del Tajo, recoja las aguas de la vertiente septentrional de Gredos ${ }^{10}$.

El alto Tormes constituye un corredor situado sobre los 1500-1400 m de altura y abierto hacia el norte, donde se une a otra fosa, la del Aravalle, que con dirección NE pone en contacto los puertos de Villatoro y Tornavacas. Al este se sitúa la fosa del Corneja, abierta hacia el oeste,

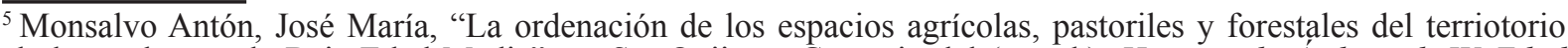
abulense durante la Baja Edad Media", en Ser Quijano, Gregorio del (coord.), Historia de Ávila, vol. IV, Edad Media (siglos XIV-XV), Ávila, Institución “Gran Duque de Alba", 2009, pp. 453-470.

${ }^{6}$ Tomé Martín, Pedro, Antropología ecológica: Influencias, aportaciones e insuficiencias, Ávila, Institución Gran Duque de Alba, 1996, pp. 319-411.

${ }^{7}$ Blanco González, Antonio, "Tendencias de uso del suelo en el valle Amblés (Ávila, España). De la Edad de Hierro al Medievo", en Zephyrus, 63 (2009), p. 156.

${ }^{8}$ Ibídem.

${ }^{9}$ Troitiño Vinuesa, Miguel Ángel, "El territorio medieval abulense y su potencial ecológico", en Barrios García, Ángel (coord.), Historia de Ávila, vol. II, Edad Media (siglos VIII-XIII), Avila, Institución "Gran Duque de Alba", 2000, pp. 67-68.

${ }^{10}$ Ibídem, pp. 94-98.
} 
delimitada por un conjunto de cerros que se adosan a la sierra de Villafranca y por otros que la separan de los bloques de Cabezas del Villar.

Figura 1: Área de estudio. En negro la provincia de Ávila, en rojo la zona de estudio.

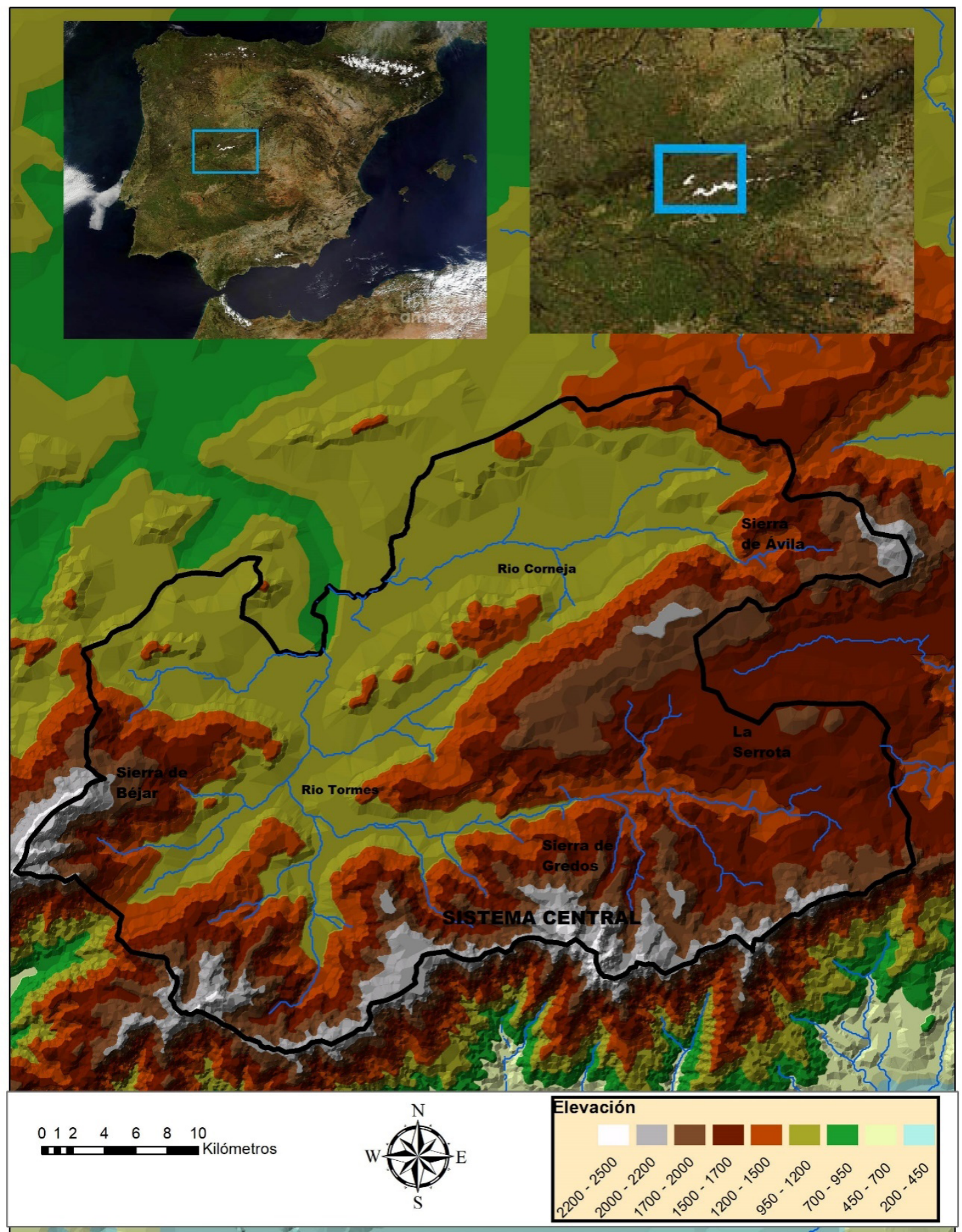

Fuente: Elaboración propia. 
Debemos destacar la importancia de las fallas, mientras que las de dirección NE sirven para la adecuación de las vías de comunicación zonales, las de dirección NW son aprovechadas por las corrientes fluviales que nacen en la sierra de Ávila para desaguar en el río Tormes.

Los datos climáticos son dispares cuando comparamos las condiciones de las cotas más elevadas con las de las más bajas. En las zonas más elevadas, los valores pluviométricos se encuentran entre 600-1200 mm/año, con unas temperaturas medias anuales que apenas sobrepasan los $3^{\circ} \mathrm{C}$. La zona intermedia del Aravalle y Tormes se caracteriza por una elevada pluviometría, entre 600-1500 mm/año, con al menos 20 días de nieve al año, lo que determina unos inviernos rigurosos, algo más suaves a medida que disminuye la altura, con un período seco que oscila de 2 a 3 meses. En cuanto a las temperaturas, se elevan a la vez que nos alejamos de las altas cumbres; las medias oscilan entre $\operatorname{los} 3^{\circ} \mathrm{C}$ y $\operatorname{los} 10^{\circ} \mathrm{C}$. Las heladas solo desparecen tres meses: junio, julio y agosto, el resto del año pueden ser muy abundantes, dependiendo de la altitud y la orientación.

La vegetación zonal está compuesta por matorral de piorno, al que se asocian otras especies, según la altitud, propia de ambientes de montaña oromediterráneos, con grupos aislados de robles en las cotas inferiores, y enebros comunes y robledales en las superiores. Hacia las cumbres aparecen pastizales alpinizados de festuca y cervunales en las zonas de mayor humedad. En las de menor pendiente, y limitadas por rocas, pueden aparecer trampales y turberas. A medida que nos acercamos a las zonas de transición a la penillanura, la vegetación se caracteriza por la presencia de encinares adehesados, que alternan con matorrales de jaras y retamas ${ }^{11}$.

\section{Metodología}

A nivel metodológico, partimos de la consulta del Inventario Arqueológico de la provincia de Ávila (IAA), de las diferentes intervenciones arqueológicas y de la información, muy heterogénea, existente sobre la zona. Se ha realizado un estudio pormenorizado de la topografía, los recursos naturales, los ejes viarios y ganaderos que podrían motivar la ubicación de un asentamiento. El estudio de los topónimos se muestra como una herramienta muy útil a la hora de mostrarnos pervivencias y transformaciones en el paisaje y corroborar la presencia o influencia de ciertos grupos étnicos sobre el territorio. Lo mismo sucede con la presencia de la epigrafía, elementos, que muchas veces aparecen aislados o fuera de contexto, pero hablan

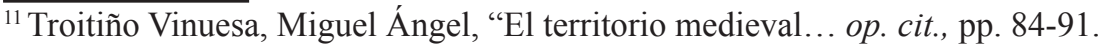


de la indiscutible presencia de poblaciones que recurrieron a su uso como instrumentos para perdurar en el tiempo.

Siguiendo la metodología utilizada por Blanco-González ${ }^{12}$, hemos clasificado los suelos agrupándolos en tres categorías en función ${ }^{13}$ de su capacidad agrícola y litología, lo que permite buscar posibles diferencias en los patrones de ubicación de los asentamientos, con la preferencia de unos tipos frente a otros en determinadas épocas históricas. Junto con las alturas donde se sitúan, distancias medias a los cursos fluviales y a las principales vías de comunicación. Todo ello ha sido integrado, gestionado y analizado a través del recurso de las TIG, apoyándose en el material cartográfico disponible en el Instituto Geográfico Nacional.

La clasificación cronocultural seguida es la que consta en las correspondientes fichas del IAA, obtenida tras la estimación de los restos arqueológicos documentados en superficie. Los resultados permiten, gracias a la escala alcanzada, obtener una perspectiva representativa de todo el territorio. Sin embargo, debemos ser cautos ante la incertidumbre de la caracterización y clasificación de los yacimientos, cuyos datos hemos sometido a la correspondiente crítica ${ }^{14}$, tratando de separar los verdaderos asentamientos del posible material off site. Con los datos obtenidos se han elaborado mapas que caracterizan las diferentes fases cronológicas junto a los ejes de comunicación, vías pecuarias y romanas. Además, se han elaborado varias tablas donde se estudió la altura media por períodos y las distancias a los cursos fluviales y vías de comunicación con el fin de poder establecer un método que pueda servir para comparar diferentes zonas.

Este estudio trata de reflejar los procesos de cambio cultural en los paisajes de esta zona de la meseta norte; estos procesos ya han sido objeto de estudio en zonas próximas, bien en el cambio cultural entre la II Edad del Hierro y época romana ${ }^{15}$, durante la época romana y tardoantigua $^{16}$ o en la transformación a la Alta Edad Media ${ }^{17}$.

Somos conscientes de las limitaciones y la complejidad que subyacen en este estudio y de que en un futuro nuevos datos pueden matizar o completar algunos de sus aspectos. También de los problemas que plantea el uso de los datos del IAA, obtenidos mediante prospección extensiva por diferentes grupos, mostrando una falta de conjunción, así como deficiencias en

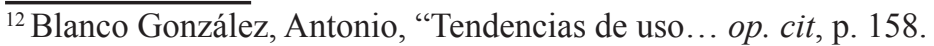

${ }^{13}$ Grupo A: Suelos que permiten cultivos permanentes y pastos, de naturaleza aluvial, en el fondo de valle. Permiten la horticultura en zonas con suficiente aporte hídrico. Grupo B: Suelos que permiten cultivos de secano y algunos pastos; son terrenos más pedregosos e inclinados, idóneos para pastoreo de carácter extensivo. Grupo C: Suelos para usos silvopastoriles extensivos y forestales. Son pedregosos y de poca potencia.

${ }^{14}$ Witcher, Robert, "Broken Pots and Meaningless Dots? Surveying the Rural Landscapes of Roman Italy", en Papers of the British School at Rome, 74 (2006), pp. 39-76. DOI: https://doi.org/10.1017/S0068246200003226

${ }^{15}$ García Sánchez, Jesús, "El poblamiento y la explotación del paisaje en la meseta norte entre la Edad del Hierro y época romana altoimperial. Una aproximación a través de la arqueología espacial”, en Zephyrus, 64 (2009), pp. 81-96.

${ }^{16}$ Reyes de Soto García, María de los, El valle del río Almar entre la II Edad del Hierro y la Alta Edad Media. Estudio de un microespacio en la Meseta Norte, tesis doctoral inédita, Universidad de Salamanca, 2015.

${ }_{17}$ Tejerizo García, Carlos et al., "La construcción histórica de los paisajes en el sector central de la cuenca del Duero. Primeros resultados de una prospección intensiva", en Territorio, sociedad y poder: revista de estudios medievales, 10 (2015), pp. 39-62.
} 
las posibles cronologías atribuidas. En cualquier caso, consideramos fundamental abordar un estudio diacrónico y de conjunto de estos territorios, hasta el momento poco estudiados, que permita no solo conocer su evolución durante estos períodos sino también ser capaces de insertarlos dentro del marco más amplio del mundo romano y tardoantiguo del centro peninsular.

Debemos tener en cuenta que la visibilidad arqueológica superficial en estas comarcas es reducida, debido al abandono de los usos agrarios tradicionales, lo que sin duda ha debido repercutir en la recogida de datos.

\section{Vías de comunicación}

Uno de los elementos de gran importancia en el análisis arqueológico es el estudio de las vías de comunicación ${ }^{18}$. Este territorio destaca por la existencia de numerosas cañadas y vías pecuarias, que recuerdan la importancia que ha tenido la ganadería en las zonas montañosas ya desde la prehistoria reciente ${ }^{19}$. Desde ese momento sabemos de la presencia de grupos ganaderos en busca de buenos pastos, cuyos recorridos harían surgir el sistema de vías pecuarias que ha llegado hasta la actualidad ${ }^{20}$. Estos movimientos periódicos, transterminancia, son practicados por grupos que mantienen una estrecha relación con el territorio que explotan.

Es lógico suponer que el actual territorio abulense fue recorrido por varios caminos romanos, abiertos ex novo o manteniendo rutas ancestrales ${ }^{21}$. Fueron los romanos quienes trazaron la primera red de caminos, con fines militares y comerciales, que se constituyó en un elemento indispensable en la romanización de la península ${ }^{22}$. Sin embargo, la escasez de datos dificulta su trazado, el establecimiento de su cronología y su evolución histórica. En esta zona no se documenta el paso de ninguna de las calzadas principales ${ }^{23}$, pero sí ramales secundarios que enlazarían con las calzadas de primera magnitud. Estos caminos enlazaban Ávila con

\footnotetext{
${ }^{18}$ Martínez Lillo, Sergio et al., "La continuidad de la red viaria de época antigua en época medieval en el valle del Tiétar abulense", en Criado del Val, Manuel (coord.), Caminería hispánica: actas del II Congreso Internacional de Caminería Hispánica, vol. 2, Guadalajara, AACHE, 1996, pp. 169-184.

${ }^{19}$ Gómez-Pantoja, Joaquín y Eduardo Sánchez Moreno, "Antes de la Mesta”, en Novoa Portela, Feliciano y Luis Vicente Elías (coord.), Un camino de ida y vuelta. La trashumancia en España, Barcelona, Lunwerg, 2003, pp. 23-35.

${ }^{20}$ Galán Domingo, Eduardo y Marisa Ruiz-Gálvez Priego, "Rutas ganaderas, transterminancia y caminos antiguos", en Gómez-Pantoja, Joaquín (coord.), Los rebaños de Gerión: pastores y trashumancia en Iberia antigua y medieval, Madrid, Casa de Velázquez, 2001, p. 277.

${ }^{21}$ García Martín, Pedro, "La principal sustancia destos reynos. De la trashumancia premesteña en la Península Ibérica”, en Gómez-Pantoja, Joaquín (ed.), Los rebaños de... op. cit., p. 14.

${ }^{22}$ Alfaro Giner, Carmen, "Vías pecuarias y romanización en la Península Ibérica”, en Gómez-Pantoja, Joaquín (ed.), Los rebaños de... op. cit., p. 218.

${ }^{23}$ Hernando Sobrino, María del Rosario, “Ávila: una ciudad con vocación ganadera”, en Mangas Manjarrés, Julio y Miguel Ángel Novillo (coord.), El territorio de las ciudades romanas, Madrid, Ediciones Sísifo, 2008, pp. 385-424; Barrios García, Ángel, Estructuras agrarias y de poder en Castilla: el ejemplo de Avila (1085-1320), Salamanca, Universidad de Salamanca, 1983, p. 102.
} 
Caesarobriga a través de la falla del Pico; con la Vía de la Plata, siguiendo los valles del Valle Amblés y del Corneja; y con Segobia por la depresión de Campozálvaro.

La calzada Ávila-Puerto de Tornavacas, eje transversal de la provincia ${ }^{24}$, puede ser rastreada por el rosario de yacimientos que la flanquean, por los restos de la propia vía, así como por la toponimia. Podemos seguir su trazado por el valle del Jerte ${ }^{25}$, puerto de Tornavacas, valle del Tormes, puerto de Villatoro, valle del Adaja hasta alcanzar la ciudad de Ávila. En la actualidad, ha quedado, en gran parte fosilizada, bajo la carretera N-110 Ávila-Plasencia. Es una ruta de gran antigüedad ${ }^{26}$, que perdurará, como camino mesteño, para el desplazamiento de los rebaños hacia Extremadura ${ }^{27}$. Se documentan sus restos en Barco de Ávila, en el puente sobre el Tormes, sobre cuya romanidad no hay acuerdo ${ }^{28}$, y en lo alto del Puerto de Tornavacas.

La vía secundaria que enlazaba Caelonico, mansio situada en la inmediación de Puerto de Béjar $^{29}$, parte de la Vía de la Plata con dirección a Béjar, donde termina el Ramal 16 de Roldán ${ }^{30}$, y se une con la vía Tornavacas-Ávila, en las cercanías de San Miguel de Corneja. Discurre por el valle del Corneja paralelamente y al norte del anterior camino. En San Bartolomé de Corneja pasa sobre el río Corneja ${ }^{31}$, y desde allí, se dirige hacia Villafranca de la Sierra, y posiblemente, hacia el Puerto de Chía ${ }^{32}$. En paralelo a esta vía, pero en la zona salmantina se documenta el Ramal $17^{33}$,que uniría la Vía de la Plata con Medina del Campo, articulando los yacimientos de las proximidades del pantano de Santa Teresa ${ }^{34}$.

La vía de Caelonico a Palacios de Goda, como la anterior, se origina en el Ramal 16 de Roldán, pero continúa a partir de Puente del Congosto en dirección NE, hacia Narrillos del Álamo, donde se localizan dos miliarios ${ }^{35}$, continúa por Diego Álvaro, hacia Palacios de Goda, recorriendo un rosario de yacimientos de cronologías altoimperiales y tardorromanas.

\footnotetext{
${ }^{24}$ Hernando Sobrino, María del Rosario, “Ávila: una ciudad... op cit., p. 394.

${ }^{25}$ Rodríguez Almeida, Emilio, Ávila Romana, Ávila, Caja General de Ahorros y Monte de Piedad de Ávila, 1981.

${ }^{26}$ Álvarez Rojas, Antonio y Juan Gil Montes, "Aproximación al estudio de las vías de comunicación en el primer milenio antes de Cristo en Extremadura", en Trabajos de Prehistoria, 45 (1988), pp. 305-316. DOI: https://doi. org/10.3989/tp.1988.v45.i0.618

${ }^{27}$ Aitken, Robert, "Rutas de trashumancia en la meseta castellana", en Estudios Geográficos, 26 (1947), pp. 193195.

${ }^{28}$ Fuente Arrimadas, Nicolás de, Fisiografia e Historia del Barco de Ávila, Ávila, 1925, p. 141; Fernández Casado, Carlos, Historia del puente en España. Puentes romanos, Madrid, CSIC, 2008; Rodríguez Almeida, Emilio, Ávila Romana,...op. cit., p. 71

${ }^{29}$ Ariño Gil, Enrique y Mónica de Quevedo, "Un epígrafe romano inédito junto a la Mansio Caelonico de la Vía de la Plata (Puerto de Béjar/Peña Caballera, Salamanca), en Zephyrus, 60 (2007), p. 265; Roldán Hervás, José Manuel, Iter ab Emerita Asturicam. El camino de la Plata. Salamanca, Universidad de Salamanca, p. 159.

${ }^{30}$ Ibídem.

${ }^{31}$ Ibídem.

${ }^{32}$ Barraca de Ramos, Pilar, "Estrategia militar y entramado viario del territorio abulense", en Gladius, Anejos, 5 (2002), p. 667.

${ }^{33}$ Roldán Hervás, José Manuel, Iter ab Emerita ...op. cit., p. 159.

${ }^{34}$ Ariño Gil, Enrique, "El yacimiento de El Cortinal de San Juan (Salvatierra de Tormes, Salamanca) y su contexto arqueológico", en Díaz Martínez, Pablo de la Cruz y Iñaki Martín Viso (coord.), Entre el impuesto y la renta: problemas de la fiscalidad tardoantigua y altomedieval, Bari, Edipuglia, 2011, pp. 251-270.

${ }^{35}$ Hernando Sobrino, María del Rosario y José Luis Gamallo Barranco, "Dos miliarios de Narrillos del Álamo, Ávila”, en Ficheiro Epigráfico, 83 (2006), pp. 375-376.
} 
Nicolás de la Fuente sugiere la existencia de otro camino que desde Barco de Ávila se dirigiría a Navalonguilla ${ }^{36}$, que discurriría cerca de la necrópolis de Huerto del Moro. También insinúa otro camino que desde Barco de Ávila por Navarredonda se encaminaría hacia el Puerto del Pico ${ }^{37}$.

\section{Toponimia}

Los topónimos nos hablan de la percepción que un grupo posee del territorio que explota, a la vez sirven de reflejo de los cambios económicos y sociales sucedidos ${ }^{38}$. La toponimia es una ayuda imprescindible a la hora de realizar estudios de carácter histórico y arqueológico y ha de servirnos como útil herramienta con la que complementar los datos obtenidos mediante otras fuentes, ofreciéndonos un valioso conjunto de indicios para el estudio del paisaje ${ }^{39}$.

En la zona de estudio perviven topónimos de gran antigüedad como Tormes ${ }^{40}$, Tormellas, Aravalle, Barco ${ }^{41}$ o Berrueco, con un claro origen prerromano. De origen romano contamos con numerosos ejemplos que hacen referencia a diversos aspectos, bien del paisaje, como Cereceda (Cercetum, "encina"), Los Loros (laurus, "laurel”), La Horcajada (furcacula, "horca”), Cabezas, Cabezuelo (capitium); bien de edificaciones como Palacios (palatium), Villar (villare) $)^{42}$, La Canaleja (canalis, canaliculia, "canalización") o bien a vías de comunicación La Carrera (carraria, "camino"). Acaso de origen germánico podemos citar Gilbuena o El Mirón ${ }^{43}$. De igual modo, permanece el mozárabe Zapardiel.

Muchos de los topónimos actuales provienen de la época medieval, fruto de la repoblación norteña de la zona, haciendo referencia a distintos aspectos paisajísticos, como sucede con los numerosísimos que recogen el término nava ${ }^{44}$ (Navamorisca, Navamediana...), indicadores de transformaciones del paisaje (Tremedal, Riofraguas...), hagiotopónimos (San Bartolomé de Béjar, Santa Lucía de la Sierra...), referencias a los fundadores (Gil García, Galindo...), flora (La Zarza), étnicos (Los Narros), etc.

\footnotetext{
${ }^{36}$ Fuente Arrimadas, Nicolás de la, Fisiografía e Historia ...op. cit., pp. 141-142.

${ }^{37}$ Ibídem, p. 141.

${ }^{38}$ Folgueira Lombardero, Pablo, "La toponimia como fuente para el estudio del poblamiento altomedieval: posibilidades y limitaciones", en Tiempo y sociedad, 1 (2009), p. 16.

${ }^{39}$ Hernández Sousa, José Miguel, “Arqueología del Paisaje... op cit., pp. 48-58.

${ }^{40}$ Tejero Robledo, Eduardo, Toponimia de Ávila, Ávila, Institución Gran Duque de Alba, 1983, pp. 133-134.

${ }^{41}$ Barrios García, Ángel, "Una tierra de nadie: los territorios abulenses en la Alta Edad Media”, en Barrios García, Ángel (coord.), Historia de Ávila... op. cit., p. 209.

${ }^{42}$ Barrios García, Ángel, "Repoblación en la zona meridional del Duero", en Studia historica. Historia medieval, 3 (1985), p. 43.

${ }^{43}$ Tejero Robledo, Eduardo, Toponimia de Ávila ...op. cit., pp. 181-182.

${ }^{44}$ Barrios García, Ángel, Estructuras agrarias y...op. cit., p. 118.
} 
Todos ellos nos hablan, por un lado, de los grupos humanos que han poblado esta zona, y por otro, de su permanencia sobre el territorio hasta la actualidad a pesar de las transformaciones sufridas en el paisaje.

\section{Estudio de los yacimientos}

\subsection{Los asentamientos durante el Hierro II}

El poblamiento en esta zona durante la II Edad del Hierro está caracterizado por un escaso número de asentamientos ${ }^{45}$ aparentemente concentrados en la parte más occidental del valle del Tormes. En la actualidad conocemos Era de los Moros y Las Paredejas ${ }^{46}$, sobre los que tenemos una desigual información. El primero es un pequeño asentamiento situado en un lugar destacado con gran control visual sobre una amplia zona; asentado sobre suelos cuya principal dedicación es la explotación forestal y silvopastoril de carácter extensivo. Son visibles pequeños restos de muros, interpretados como partes de posibles cerramientos defensivos. Las Paredejas se encuentra en el Cerro del Berrueco, lugar con una amplia ocupación humana documentada ${ }^{47}$ correspondiente a diferentes períodos históricos. En el mismo cerro se sitúa el yacimiento de Los Tejares, en la provincia de Salamanca. Ambos se encuentran en la base del cerro y ninguno cuenta con sistemas defensivos. Los materiales de Las Paredejas aportan una cronología entre los siglos VII y III a. C. Posiblemente fue abandonado antes del siglo i a. C., en relación con el surgimiento de Los Tejares, que perdurará hasta el siglo III d. C. ${ }^{48}$.

Las alturas en las que se emplazan estos yacimientos oscilan entre los $1080 \mathrm{~m}$ de Las Paredejas y los $1200 \mathrm{~m}$ de la Era de los Moros.

Tanto Era de los Moros como Las Paredejas cuentan con una prolongada secuencia de ocupación que arranca en la I Edad del Hierro, hasta un momento previo al cambio de Era. Su abandono debemos ponerlo en relación con la llegada de los romanos y las transformaciones que se suceden en los modelos productivos; en ninguno de ellos parece detectarse un abandono motivado por los avatares de la guerra.

\footnotetext{
${ }^{45}$ Álvarez-Sanchís, Jesús, Los Vettones, Madrid, Real Academia de la Historia, 1999, pp. 102-103; Hernando Sobrino, María del, Indigenismo y romanización del territorio abulense (s. $V$ a.C.-s. III d.C.). tesis doctoral, Universidad Complutense de Madrid, 2003, pp. 284-286.

${ }^{46}$ Fuente Arrimadas, Nicolás de la, Fisiografía e Historia ... op. cit., p. 18.

${ }^{47}$ Fabián García, José Francisco, "El Bronce final y la Edad del Hierro en "El Cerro del Berrueco" (ÁvilaSalamanca)", en Zephyrus, 39-40 (1986-1987), pp. 273-287.

${ }^{48}$ Ibídem, p. 281.
} 
21 José Miguel Hernández Sousa, "Paisajes culturales de la Antigüedad en los valles...”

Figura 2: Relación de los yacimientos incluidos en el estudio.

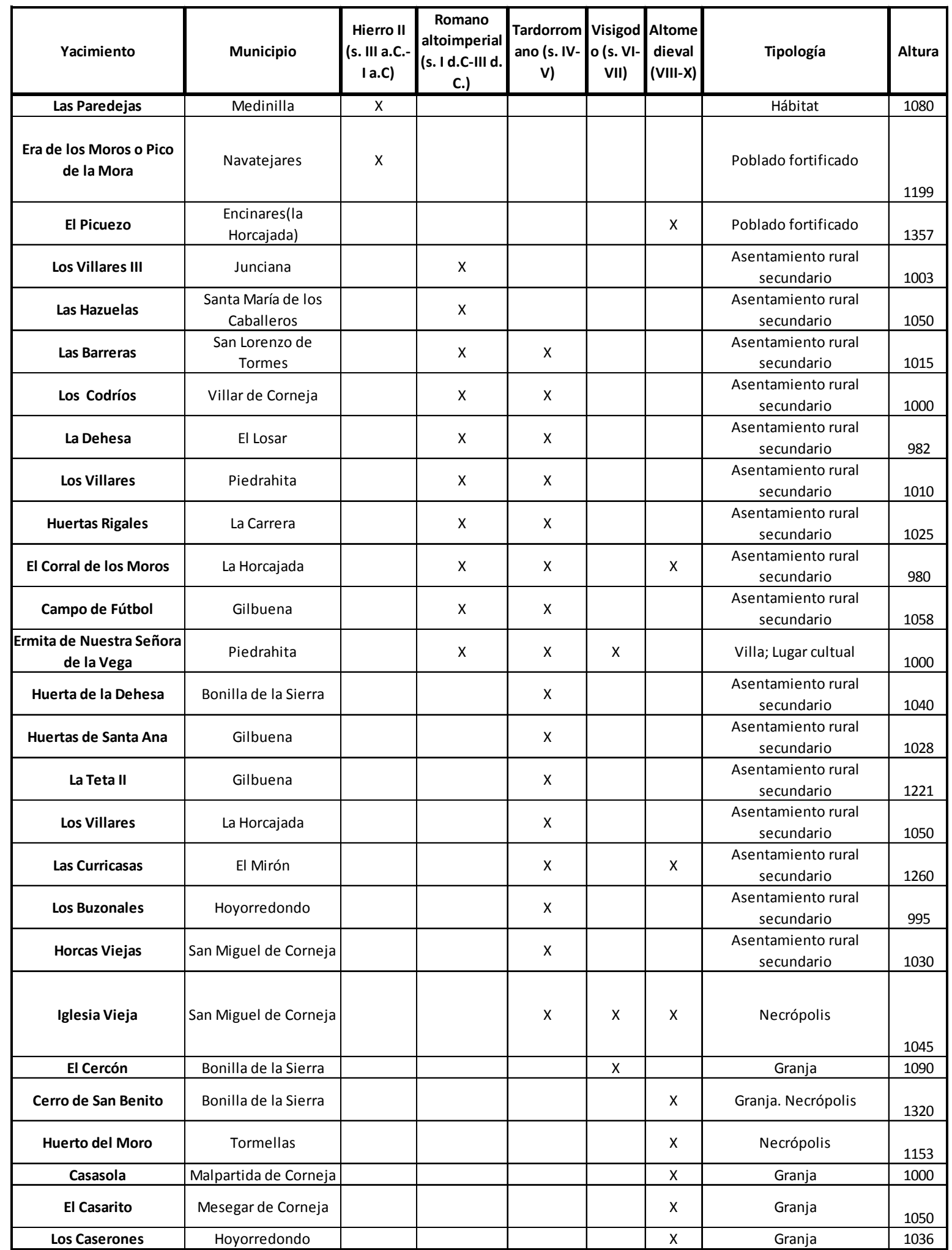

Fuente: Elaboración propia. 
Figura 3: Relación de yacimientos y tipos de suelos. 1. Huerto del Moro, 2. Era de los Moros, 3. Huerta Rigales, 4. Las Barreras, 5. La Dehesa, 6. Las Hazuelas, 7. Huertas de Santa Ana, 8. Campo de Fútbol, 9. La Teta II, 10. Los Villares III, 11. Las Paredejas, 12. El Corral de los Moros, 13. El Picuezo, 14. Los Caserones, 15. Los Villares, 16. Los Buzonales, 17. Los Codríos, 18. Las Curricasas, 19. Casasola, 20. El Casarito, 21. Ermita de Nuestra Señora de la Vega, 22. Las Villares, 23. Horcas Viejas, 24. Iglesia Vieja, 25. Huerta de la Dehesa, 26. Cercón, 27. Cerro de San Benito.

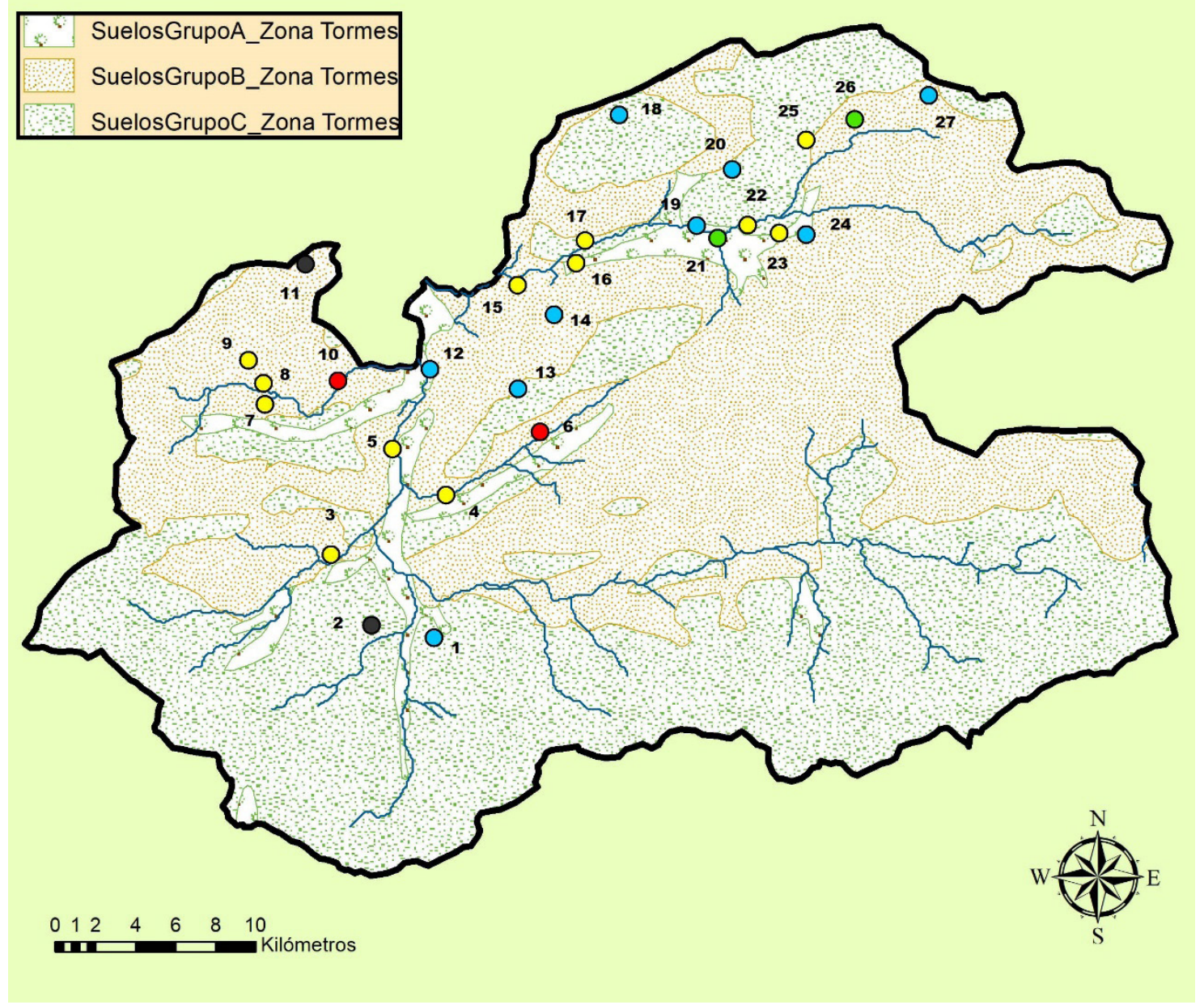

Fuente: Elaboración propia.

Conocemos la presencia de varias esculturas zoomorfas, una de las manifestaciones prerromanas de la zona. En Las Paredejas apareció hace años una figura en granito en una de las cercas del yacimiento, representando un cerdo; actualmente se encuentra en el Puente del Congosto (Salamanca) ${ }^{49}$. Otros dos verracos fueron hallados en las proximidades de Villanueva del Campillo ${ }^{50}$, uno de un toro y la otra un posible suido. En Bonilla de la Sierra se localizó otro; en la actualidad se desconoce su paradero ${ }^{51}$. Ya en la provincia de Salamanca, en Santibáñez

\footnotetext{
${ }^{49}$ Álvarez-Sanchís, Jesús, Los Vettones ...op. cit., p. 251, nº 84, fig. 103.2.

${ }^{50}$ Ibídem, p. 355, ${ }^{\circ} 1$.

${ }^{51}$ Arias Cabezudo, Pilar et al., Catálogo de la escutura zoomorfa protohistórica y romana de tradición indígena en la provincia de Avila, Ávila, Institución "Gran Duque de Alba”, 1986, p. 141.
} 
de Béjar ${ }^{52}$, se encontró un cerdo; en El Tejado se localizaron cuatro toros, uno de ellos de grandes dimensiones, todos muy próximos al Cerro del Berrueco. Es sabido que su significado e interpretaciones son muy dispares y que es difícil establecer las razones para las que fueron creadas $^{53}$. Posiblemente las de mayores dimensiones, como son la mayoría de los encontrados en esta zona, debieron usarse como marcadores de $\operatorname{pastos}^{54}$.

Figura 4: Yacimiento de cronología Hierro II y su relación con las esculturas en piedra de verracos y vías de comunicación existentes en la zona.

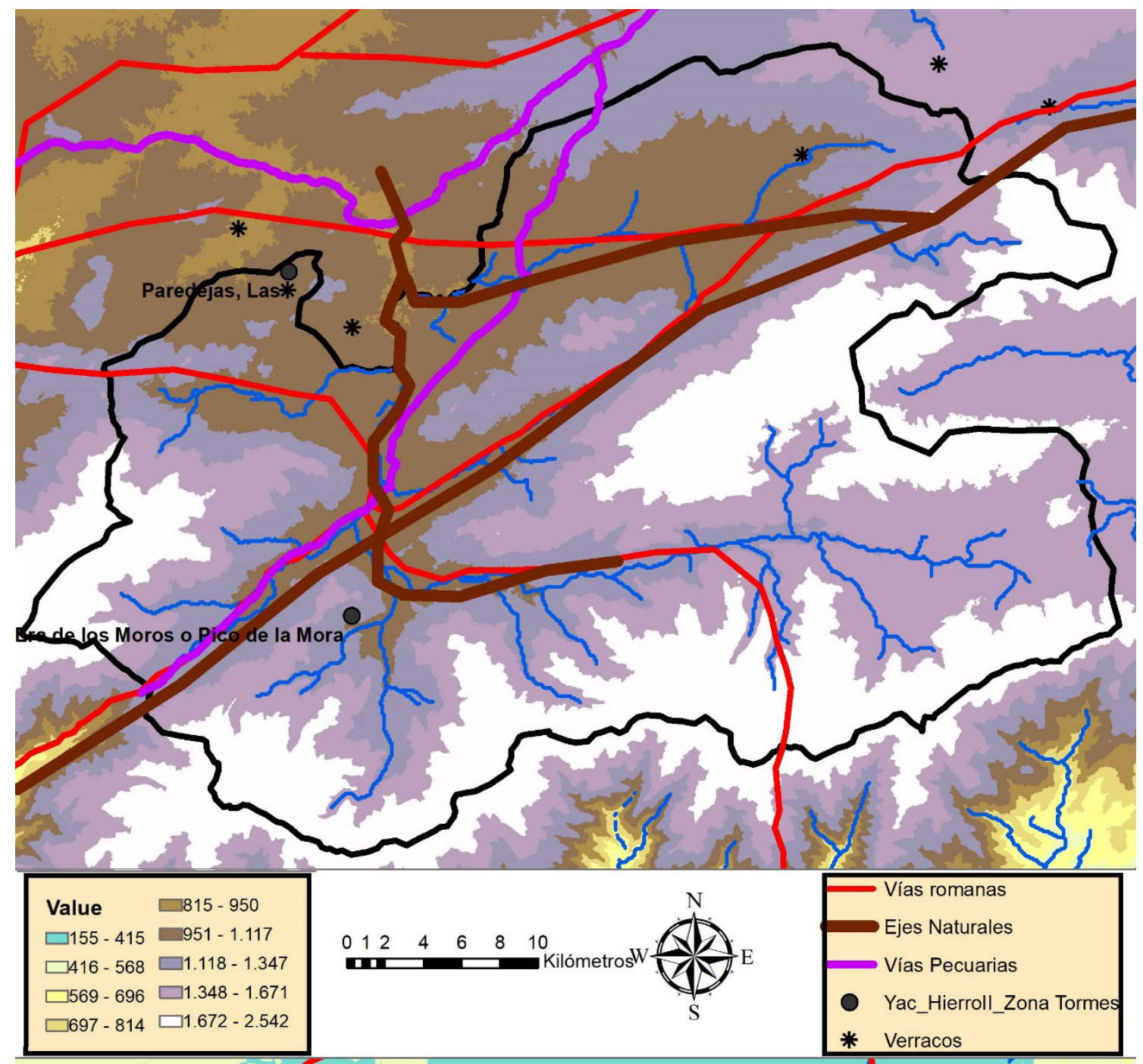

Fuente: Elaboración propia.

\footnotetext{
${ }_{52}$ Álvarez-Sanchís, Jesús, Los Vettones...op. cit., p. 349.

${ }^{53}$ Manglano Valcarcel, Gregorio, Los verracos, un patrimonio arqueológico singular en el ámbito de la Península Ibérica. Estudio de los contextos de aparición y procedencia, identificación funcional y valoración patrimonial. Tesis Doctoral Inédita, Universidad Autónoma de Madrid, 2013, pp. 110-130.

${ }^{54}$ Álvarez Sanchís, Jesús, “Ciudades vettonas”, en Complutum, 22 (2), 2011, p. 163.
} 
Son muy escasos el número de yacimientos enumerados, pese a que contamos con algunas evidencias que sugieren la posibilidad de la existencia de un mayor número, aunque por ahora no hayan sido localizados, sitios como Barco de Ávila o Villanueva del Campillo son lugares donde podrían localizarse otros asentamientos. La presencia de verracos nos sugiere la posibilidad de la cercanía de algún asentamiento todavía no documentado.

\subsection{El poblamiento de época romana}

Contamos, hasta el momento con diez yacimientos, nueve calificados como asentamientos rurales secundarios sin poder entrar en mayores especificaciones, puesto que no han sido objeto de intervenciones arqueológicas. El único en el que se han realizado estas intervenciones es una villa, de carácter rural, la Ermita de Santa María de la Vega, situada junto al río Corneja, con una cronología que abarca desde época romano bajoimperial a visigoda ${ }^{55}$. En ella se han encontrado restos de $\operatorname{mos} \cos ^{56}$, junto a ladrillos, cerámicas, vidrio, fragmentos de columnas y de mármol ${ }^{57}$.

Los yacimientos de cronología romana altoimperial se asientan en la vega de los ríos Tormes, Aravalle y Corneja, buscando los lugares más bajos, con los suelos más productivos, donde se puedan realizar labores hortícolas y agrícolas, con una altura media de $1012 \mathrm{~m}$. Todos se localizan en las proximidades de las vías de comunicación que articulan el territorio; debemos tener en cuenta que esta percepción, tal vez no sea tal, dado el precario nivel del conocimiento que tenemos sobre las vías de comunicación a nivel local.

En todos se documenta la existencia de restos constructivos; en algunos de ellos mampostería de granito en seco (Corral de los Moros, Los Villares); en todos tégula plana, ladrillos macizos, ímbrices y en el Corral de los Moros, pizarra. Estos restos hablan de construcciones de pequeño tamaño, escaso porte, realizadas en materiales locales, principalmente con cubiertas de materiales cerámicos, lo que no descarta la posibilidad que algunas estuvieran cubiertas con materiales perecederos.

En cuanto a los materiales cerámicos, aparecen dos tipos principales de cerámicas: de cocina y de almacenamiento. Los materiales de almacenamiento, tipo dolia, aparecen en Las Hazuelas y Los Villares, se trata principalmente de pastas poco decantadas, de cocción oxidante o mixta, con tonalidades pardas y superficies con alisados toscos. En las de cocina se trata de restos de ollas con pastas poco decantadas. También se documentan cerámicas de mesa TSH (Las Hazuelas, Los Codríos, La Dehesa, Los Villares y Campo de Fútbol).

\footnotetext{
${ }^{55}$ Villa romana que en los siglos IV o v fue transformada; parte de esta fue un lugar de culto que más tarde se convirtió en ermita en Mariné, María, "La época romana", en Mariné, María (coord.), Historia de Ávila, vol. I. Prehistoria e Historia Antigua, Ávila, Institución "Gran Duque de Alba", 1995, p. 325.

${ }^{56}$ Anónimo, Informe sobre los restos hallados junto a la Ermita de Santa María de la Vega (Piedrahita). Informe técnico inédito, Museo Provincia del Ávila, 1981.

${ }^{57}$ Mariné, María, "La época romana... op. cit., p. 325.
} 
También se documentan una inscripción en Barco de Ávila ${ }^{58}$ y de sendos epitafios en Gilbuena y San Bartolomé de Tormes.

Figura 5: Yacimiento de cronología Romano alto y bajo imperial y tardorromanos y su relación con los milarios y vías de comunicación.

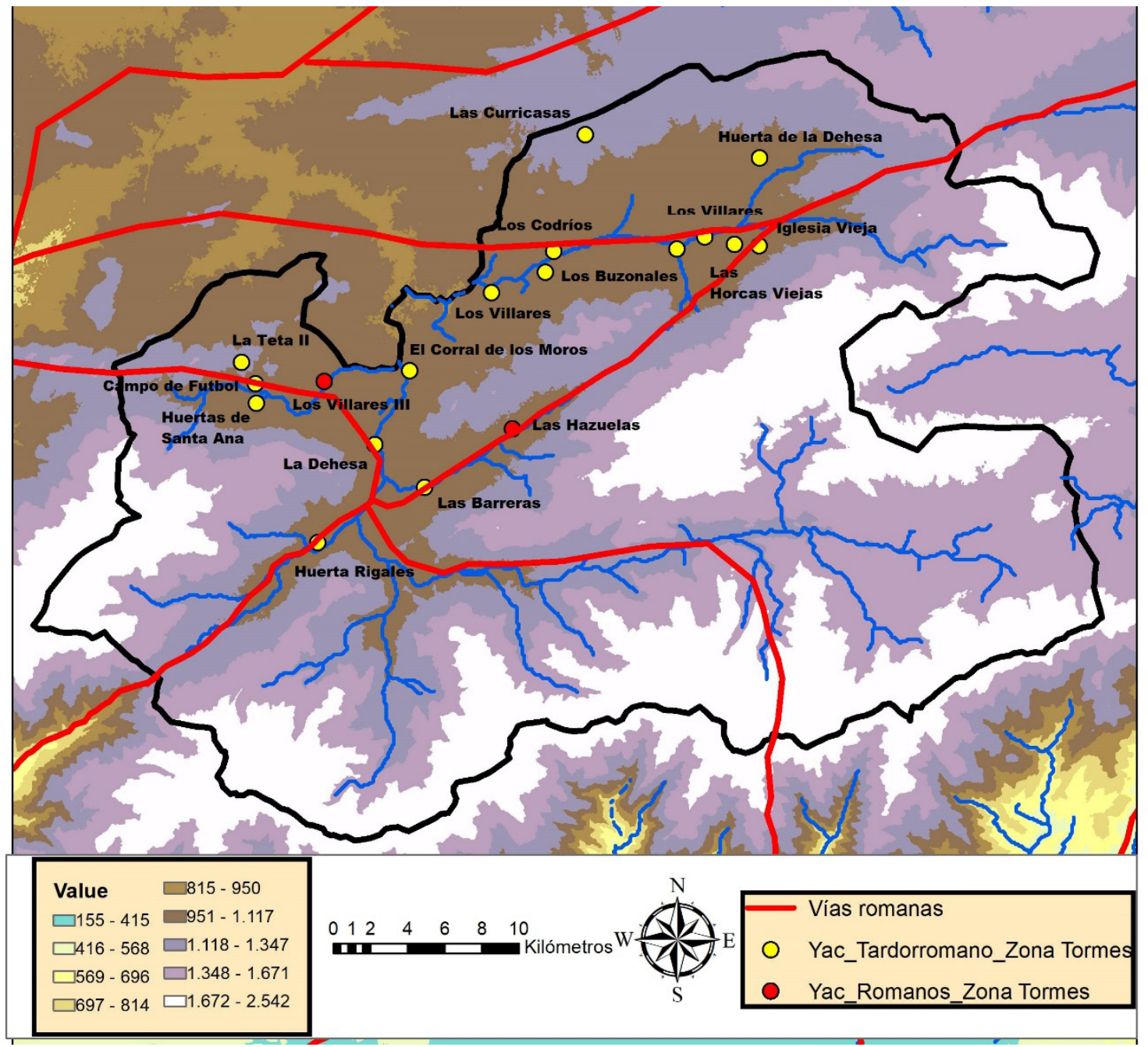

Fuente: Elaboración propia.

\footnotetext{
${ }^{58}$ Goméz-Pantoja, Joaquín y David Martino García, “Una estela en el Barco de Ávila”, en Ficheiro Epigráfico, 144 (2017), 591, donde se habla de la presencia de algunos yacimientos ya consignados dentro del presente trabajo.
} 


\subsection{Yacimientos tardorromanos}

Parece que los yacimientos del momento anterior, con excepción de Los Villares III y Las Hazuelas, mantienen la ocupación en este momento, lo que unido a los que surgen ex novo, sugieren una ocupación del territorio más densa que en los momentos anteriores y posteriores.

De los yacimientos altoimperiales con perduración tardorromana, en Los Codríos, La Dehesa y Los Villares se documentan TSHT, de pastas anaranjadas con cocciones oxidantes o mixtas, algunas con decoraciones incisas, y una estampillada, en Los Codríos, cuya adscripción cronológica tal vez debiera ser de época visigoda.

Los yacimientos se sitúan en las proximidades de las vías de comunicación, con una altura media de $1048 \mathrm{~m}$. La mayoría busca los suelos de mayor capacidad productiva, siguiendo la tendencia de los asentamientos anteriores, en las vegas de los ríos; pese a ello, hay algunos que se sitúan en emplazamientos de altura como La Teta II y Las Curricasas, situado en una loma, donde se aprecian restos constructivos además de un posible horno cerámico. Estos yacimientos parecen mostrar un cambio de estrategia de ocupación o explotación del territorio, con el uso de sitios en altura que anteriormente no habían sido utilizados; no son lugares que presenten sistemas defensivos

Todos los yacimientos, salvo la Teta II, presentan restos constructivos, tégulas, tejas curvas y, en algunos casos, mampuestos de granito de pequeño tamaño.

\subsection{Yacimientos de época visigoda}

Los yacimientos con materiales propiamente de época visigoda son escasos. Se asientan sobre suelos dedicados a la explotación agrícola, con una altura media de $1045 \mathrm{~m}$, próximos a los cursos fluviales, aunque algo más alejados que en la época tardorromana, y bastante más alejados de las vías de comunicación.

El Cercón donde contamos con cerámicas a torneta, de cocción reductora, pastas poco decantadas con desgrasantes micáceos y calizos, y superficies muy cuidadas, con acabado bruñido. Iglesia Vieja es el único yacimiento donde se han documentado pizarras escritas o numerales, que debemos poner en relación con el yacimiento cercano de Lancha de Trigo ${ }^{59} \mathrm{y}$ al conjunto de El Cortinal de San Juan ${ }^{60}$, también presenta restos constructivos. En este yacimiento se recuperaron varios sarcófagos monolíticos junto a una necrópolis de tumbas de lajas. En Solana de Ávila se documenta un sarcófago monolítico en granito, que puede ser atribuido a este momento cultural o al inmediatamente posterior, en el lugar de hallazgo se documentan fragmentos de cerámica de pastas poco decantadas con cocciones reductoras o mixtas.

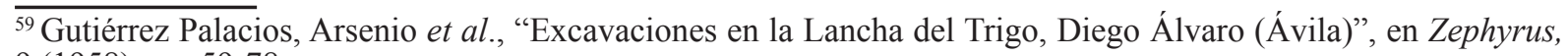
9 (1958), pp. 59-78.

${ }^{60}$ Ariño Gil, Enrique, “El yacimiento de... op. cit., pp. 251-270.
} 
El Cercón nos presenta dudas en considerarlo asentamiento o un punto de concentración de material disperso -off site-.

Figura 6: Relación del número de yacimientos por etapas cronoculturales y alturas medias de cada una de ellas.

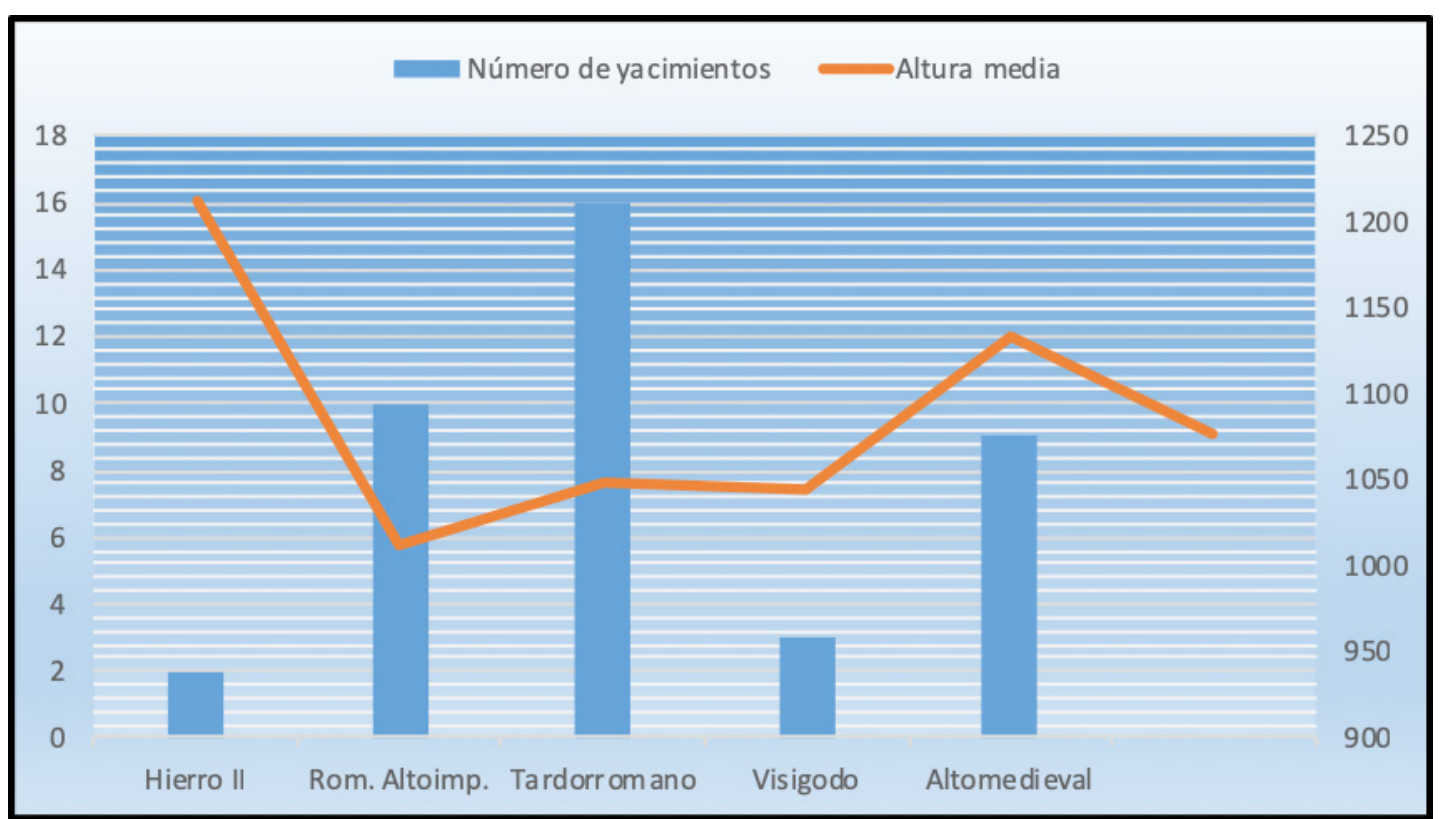

Fuente: Elaboración propia.

\subsection{Yacimientos altomedievales}

Un elemento que caracteriza a los yacimientos del periodo visigodo y altomedieval es la aparición de tumbas excavadas en la roca, a pesar de los problemas de datación que presentan ${ }^{61}$.

Los yacimientos de este periodo cultural parecen de nueva creación, rompiendo con los momentos anteriores, aunque pueda existir alguna continuidad; se emplazan en lugares de mayor altura, $1133 \mathrm{~m}$ de media, preferentemente en cimas o laderas de cerros, buscando otros tipos de suelos diferentes, propios de una explotación forestal y silvopastoril de carácter extensivo. Son los que más se alejan de las vías de comunicación y de los cursos fluviales.

Algunos de ellos plantean dudas en su consideración como asentamientos o solo puntos de hallazgos cerámicos, como sucede con el Picuezo, Los Caserones o Huerto del Moro, donde se documentan escasos restos cerámicos y no hay evidencias de estructuras o restos constructivos.

\footnotetext{
${ }^{61}$ Hernández Sousa, José Miguel, "El fenómeno de las tumbas excavadas en la roca en la cuenca alta del río Manzanares (Madrid) y su relación con el poblamiento rural”, en Revista Historia Autónoma, 9 (2016), pp. 29-50.
} 
Figura 7: Yacimiento de cronología visigoda y altomedieval.

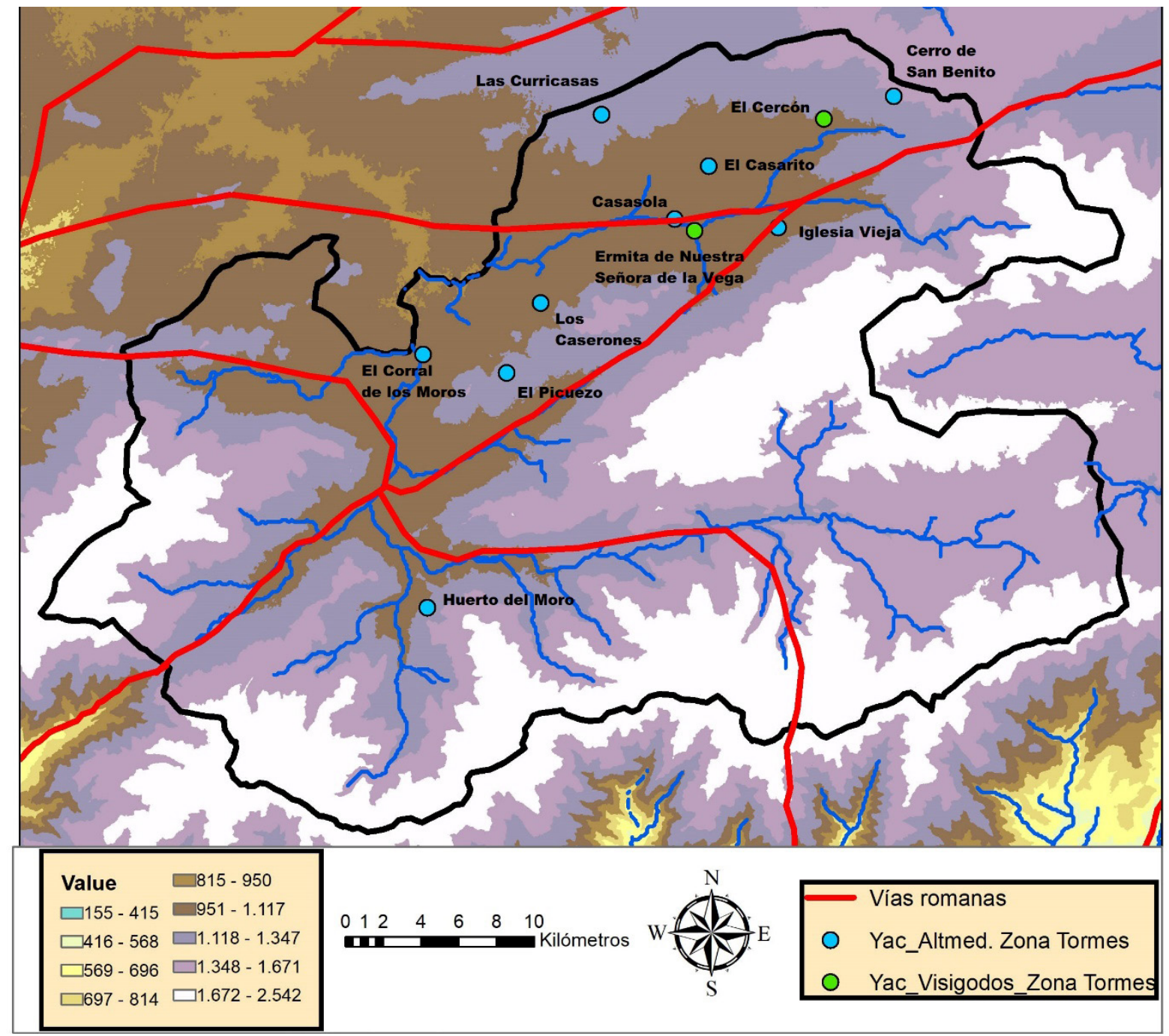

Fuente: Elaboración propia.

En Prado de la Casa se documenta una única tumba antropomorfa en la roca sin otros restos arqueológicos. En Fuente de la Madera dos tumbas antropomorfas en la roca, junto a restos de hábitat. En Cocina de los Moros se detectan cuatro estructuras de planta rectangular, con muros de mampostería en granito posiblemente trabados con barro; una tumba excavada en la roca en un bloque de granito exento; junto a ellos aparecen materiales cerámicos escasos y poco significativos: piezas de tamaño mediano, orzas u ollas a torneta, con pastas poco decantadas, desgrasantes micáceos, cocciones mixtas, con pastas de color marrón clara sin acabado exterior y sin decoración. 
Figura 8: Relación entre los yacimientos y las distancias medias a los cursos fluviales y a las vías de comunicación.

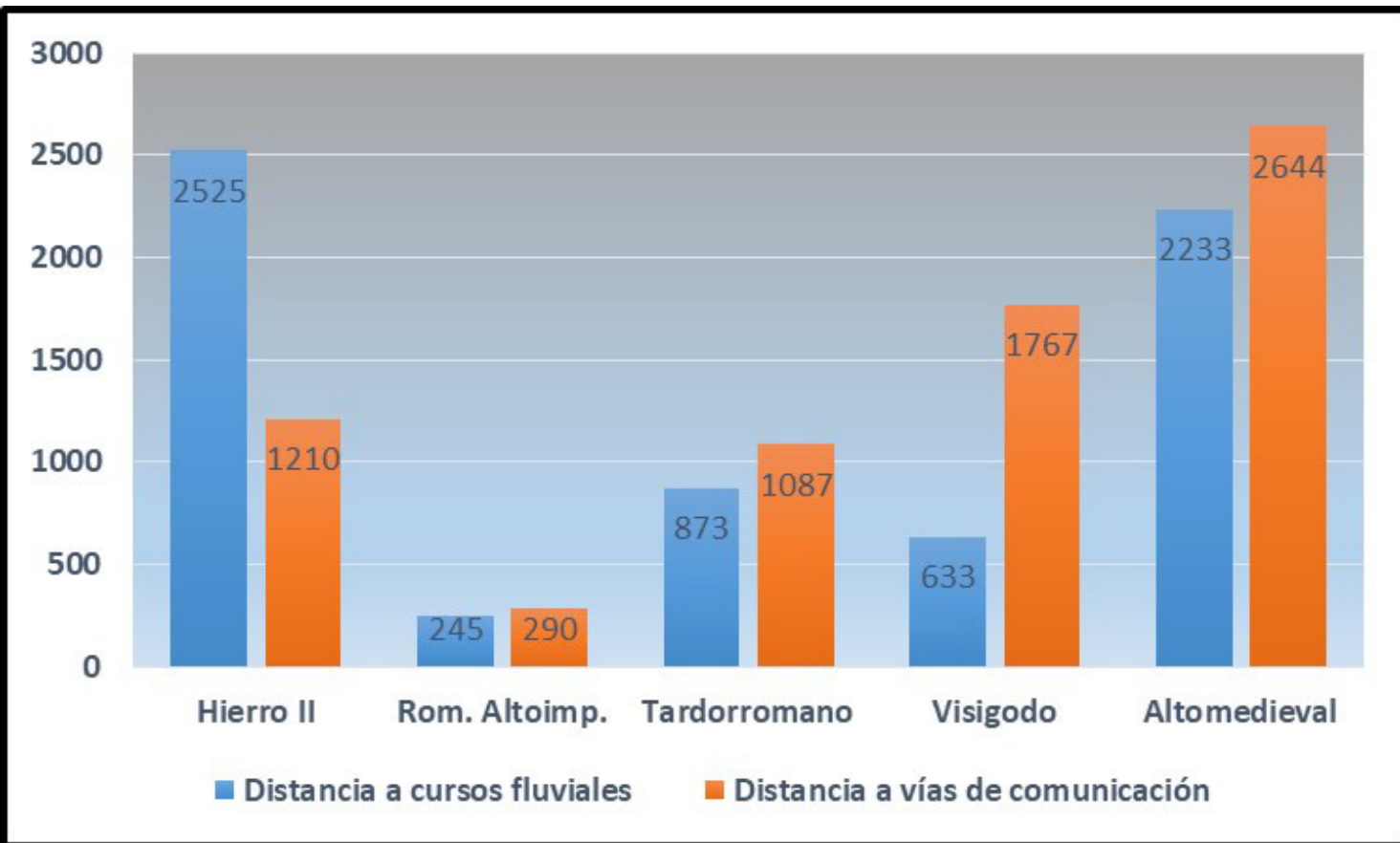

Fuente: Elaboración propia.

En el Canto de la Sepultura, emplazado en una ladera, aparecen cuatro tumbas excavadas en la roca junto a los restos del posible hábitat. El Cerro de San Benito situado en la cima de una colina, donde aparece una tumba excavada en la roca, numerosos restos constructivos, restos cerámicos realizados a torneta, cocción reductora, con desgrasantes cuarcíticos y micáceos de tamaño pequeño y acabado tosco al exterior. El Casarito, también en una colina, donde se documentan numerosos restos constructivos de una edificación cuadrangular. Casasola se sitúa junto a la vega del río, donde se documentan restos constructivos, cerámica a torno, de pastas negras y parduzcas, con cocciones reductoras y algún resto con decoración incisa de líneas onduladas paralelas.

Los Caserones se localiza en una suave pendiente sobre la margen izquierda del río Corneja; se documenta material cerámico a torno y a mano; de los realizados a mano hay algunos fragmentos de cocción reductora, desgrasantes calizos y cuarcíticos y superficies alisadas. En las realizadas a torno son pastas poco decantadas con desgrasantes calizos, cuarcíticos y micáceos con cocciones mixtas. El Huerto del Moro, se emplaza en la vega de la Garganta de los Caballeros, donde se asentaba una posible necrópolis. El Picuezo se sitúa en una colina, con una ocupación altomedieval. 


\section{Evolución del poblamiento}

Dentro de la transformación que sufre el poblamiento, debemos tener en cuenta, la escasez en el número de yacimientos investigados, puesto que en algunos de los períodos establecidos son realmente escasos; a su vez, la cronología establecida para los asentamientos que presenta cierto grado de incertidumbre, principalmente debido a la metodología utilizada en el reconocimiento de estos, prospección extensiva. Pese a ello, es posible extraer ciertas conclusiones que debemos proponer como hipótesis de trabajo.

Una primera conclusión, a pesar de lo escaso de los datos, es que a lo largo del tiempo nos encontramos ante la progresiva ocupación del territorio. Partiendo de una II Edad del Hierro caracterizada por la presencia de escasos asentamientos, le sucede una colonización más plural del territorio, de carácter rural, mediante la aparición de pequeños núcleos desde época altoimperial. El período tardoantiguo muestra una tendencia progresiva al aumento de asentamientos y la progresiva colonización de espacios que anteriormente se habían mantenido al margen del poblamiento; tendencia que se acelera en los períodos posteriores.

\subsection{La II Edad del Hierro}

Se percibe una concentración de los asentamientos en la zona occidental del valle del Tormes y posiblemente la existencia en la zona oriental del valle del Corneja, aunque esta visión puede estar condicionada por los escasos datos del IAA. Se sitúan por encima de los $1200 \mathrm{~m}$ de media, evitando zonas de mayor elevación, que implicarían unas condiciones muy duras; emplazamiento condicionado por las características de medio, con gran control visual sobre el territorio inmediato, excepto Las Paredejas. Son asentamientos en los que debemos suponer un elevado grado de autosuficiencia ${ }^{62}$, centrada preferentemente en la ganadería, con pastos de altura, complementada con la explotación forestal y agricultura ${ }^{63}$, cuyas huellas apenas percibimos.

Debemos suponer un entorno muy antropizado a su alrededor, fruto de largos períodos de explotación, como muestran los estudios palinológicos realizados en lugares próximos ${ }^{64}$, donde las masas boscosas son progresivamente sustituidas por pastizales, producto de una dedicación agropastoril ${ }^{65}$.

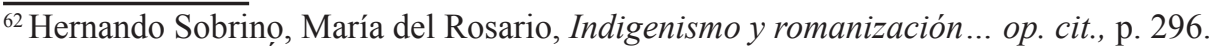

${ }^{63}$ Esparza Arroyo, Ángel, "Economía de la Meseta Prerromana”, en Estudios de Economía Antigua en la Península Ibérica. Nuevas Aportaciones. Studia Historica. H. ${ }^{a}$ Antigua, 17 (1999), p. 91.

${ }^{64}$ López-Merino, Luis et al., "2000 years of pastoralism and fire shaping high-altitude vegetation of Sierra de Gredos in central Spain", en Review of Palaeobotany and Palynology, 158 (2009), pp. 42-51. DOI: https://doi.org/10.1016/j.revpalbo.2009.07.003

${ }^{65}$ Blanco González, Antonio, "Tendencias de uso... op . cit., p. 162.
} 
La conquista efectiva de la Meseta y de esta zona en concreto, se iniciará con las guerras lusitanas y celtibéricas, entre 154 y 133 a. C. Parece que a partir de ese momento se produce el declive de los asentamientos, como parece suceder en Las Paredejas cuya población se trasladaría a Los Tejares. Situación repetida en muchos castros abulenses, abandonados a lo largo del siglo I a. C., cuando la conquista romana y la revuelta sertoriana ${ }^{66}$ ponen fin a la organización política y economía indígenas ${ }^{67}$. Las poblaciones de los asentamientos descendieron a lugares más llanos, bien por iniciativa propia u obligadas ${ }^{68}$, surgiendo con ello un nuevo modelo de poblamiento.

Con las reformas realizadas por Augusto tras la conquista de Hispania ${ }^{69}$, se crean tres provincias: mantuvo los límites de la Citerior y dividió la Ulterior en dos nuevas: la Bética y la Lusitania, cada una de ellas dividida en conventus o subdivisiones jurídicas ${ }^{70}$. Dentro de este sistema administrativo este territorio quedó encuadrado en la provincia Lusitana, junto con la mayoría del territorio vettón, y dentro de ella, en el conventus Emeritensis ${ }^{71}$. Esta organización se mantuvo vigente durante todo el período altoimperial; tampoco parece que las reformas administrativas llevadas a cabo por Diocleciano afectaran a esta zona.

Desconocemos, hasta el momento a que civitas podía pertenecer administrativamente este territorio; las ciudades más próximas conocidas son Ávila, Cápara y Salamanca, todas ellas bastante alejadas. La más cercana era Cápara, aunque las dificultades de comunicación serían mayores debido a la situación geográfica. Podemos pensar que la zona pudo pertenecer a la civitas abulense, puesto que, tras la repoblación medieval, el alfoz abulense ocupó toda la zona incluso trasponiendo el límite de las sierras ${ }^{72}$.

El progresivo abandono de los castros fue transformando el modelo de ocupación del territorio, con el surgimiento de pequeñas aldeas o granjas, situadas en terrenos más favorables para el desarrollo de una economía agrícola más acorde al nuevo modelo introducido por los romanos.

La economía del pastoreo trashumante estacional, modelo que ya existía a fines de la Edad del Bronce, prosiguió durante la del Hierro, continuó en la época romana, cuando se refugió en áreas marginales y perduró hasta el Medievo cuando volvió a alcanzar gran desarrollo ${ }^{73}$. Este

\footnotetext{
${ }^{66}$ Martín Valls, Ricardo y Ángel Esparza Arroyo, "Génesis y evolución de la Cultura Celtibérica”, en Paleoetnología de la Península Ibérica. Complutum, 2-3 (1992), pp. 274-275; Álvarez-Sanchís, Jesús et al., "El “oppidum” vettón de Ulaca (Solosancho, Ávila) y su necrópolis", Zona Arqueológica, 12 (2008), p. 347.

${ }^{67}$ Salinas de Frías, Manuel, Los vettones. Indigenismo y romanización en el occidente de la meseta, Salamanca, Ediciones Universidad de Salamanca, 2001.

${ }^{68}$ González-Tablas Sastre, Francisco Javier, "Los castros del occidente romano salmantino. Edad del Hierro y romanización”, en Zephyrus, 63 (2008), p. 146.

${ }^{69}$ Ozcáriz Gil, Pablo, Administración de la provincia Hispania Citerior durante el Alto Imperio Romano, Barcelona, Servicio de Publicaciones Universidad de Barcelona, 2013, p. 71.

${ }^{70}$ Dopico Caínzos, María Dolores, "Los “conventus iuridici”. Origen, cronología y naturaleza histórica", en Gerión, 4 (1986), pp. 265-284.

${ }^{71}$ Rodríguez Almedia, Emilio, Ávila Romana... op. cit., pp. 15-19; Knapp, Robert, Latin Inscripcion from Central Spain, Berkeley, University of California Press, 1992, pp. 6-7.

${ }^{72}$ Fuentes Domínguez, Ángel, "Una zona marginal de Hispania: Madrid en época romana", en Boletín de la Asociación Española de Amigos de la Arqueología, 39-40 (2000), p. 205.

${ }^{73}$ Fuentes Domínguez, Ángel, "Escenarios de la plena romanización en Castilla-La Mancha", en Fuentes Domínguez, Ángel (ed.), Castilla-La Mancha en época romana y Antigüedad tardía, Ciudad Real, Almud, 2006, p. 125 .
} 
tipo de economía pastoril debió coexistir en el tiempo con la economía agrícola de modelo romano en zonas como esta, aunque con un perfil muy bajo hasta que, de nuevo en la época altomedieval, comienza a tomar mayor importancia.

\subsection{La implantación y perduración del sistema romano}

La romanización de esta área se ha considerado como escasa y tardía, con fuerte persistencia de elementos culturales indígenas ${ }^{74}$.

Una zona que percibe el impacto romano acaecido en la provincia lusitana, mostrando un incremento del poblamiento disperso de carácter rural.

A partir de época flavia parece que se generaliza la ocupación del territorio, incluyendo los diversos dominios altitudinales, a excepción de las zonas más elevadas. Dadas las características de los suelos, con una clara preferencia por la explotación ganadera y forestal, los asentamientos que aprovechan los terrenos más fértiles son escasos, destacando la villa de la Ermita de Nuestra Señora y la existente en Puente del Congosto, semejantes a otras situadas en las llanuras más septentrionales ${ }^{75}$, aunque con restos monumentales de menor entidad.

Una estructura que parece estar constituida por pequeños asentamientos, que parecen organizados desde las escasas villae rurales conocidas. En estos momentos, podemos hablar de una fuerte antropización de los valles fluviales, tanto del Corneja como del Becedillas.

Este modelo establecido a lo largo del siglo i d. C. debió perdurar hasta, al menos, el siglo IV, cuando comienzan a intuirse transformaciones en el sistema. Las villae parecen perder su fuerza como elementos rectores, entre finales del siglo IV o principios del siglo v, como sucede en otros territorios cercanos ${ }^{76}$, cediéndosela a un conjunto de asentamientos en altura, con una cronología no bien establecida, pero netamente desvinculados del poblamiento prerromano. Entre ellos podemos citar La Teta II, El Risco (Santibáñez de Béjar, Salamanca) y el cerro del Castillo (El Mirón) enclave desde el que se controla el valle del río Corneja.

\subsection{La época visigoda (siglos VI-VIII)}

Si bien la calidad de la información existente no permite sacar conclusiones definitivas, parece apreciarse un retraimiento del poblamiento entre el momento tardorromano y el inmediatamente posterior. El modelo de ocupación y explotación tardorromana parece

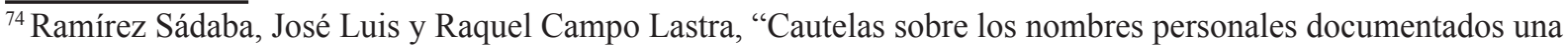
sola vez: el ara dedicada a Cabvniaegino", en Palaeohispanica 10 (2010), pp. 447-459.

${ }^{75}$ Quintana López, Javier e Inés Centeno Cea, “Una ciudad integrada... op. cit., p. 98; Fabián García, José Francisco, "Los orígenes de la ciudad de Ávila y la época antigua. Aportaciones de la Arqueología al esclarecimiento de las cuestiones históricas previas a la etapa medieval", en Luis López, Carmelo (ed.), Ávila en el tiempo. Homenaje al profesor Ángel Barrios, Ávila, Institución “Gran Duque de Alba”, 2007, p. 100.

${ }^{76}$ Ariño Gil, Enrique et al., "Patrones de ocupación rural en el territorio de Salamanca. Antigüedad Tardía y Alta Edad Media", en Caballero Zoreda, Luis et al., (coord.), Visigodos y omeyas: el territorio. Madrid, CSIC, 2012, p. 123.
} 
transformarse. Son pocos los asentamientos con materiales de esta época reconocidos, alguno de ellos pudiera tener ocupación tanto en momentos anteriores como posteriores, dadas las dificultades para diferenciar estos momentos cronológicos con materiales tan escasos y poco significativos.

Parece que los asentamientos están articulados desde lugares fuera del área de estudio, aunque también es posible que lugares como Santibáñez de Béjar ${ }^{77}$ o El Barco de Ávila ${ }^{78}$, ejercieran esta función, lugar este donde podría haber existido un edificio religioso, alguno de cuyos elementos decorativos aparecen en las murallas del casillo barcence ${ }^{79}$.

Hay que tener en cuenta la proximidad de los yacimientos en las proximidades del pantano de Santa Teresa, entre los que destaca El Cortinal de San Juan (Salvatierra de Tormes, Salamanca $)^{80}$, interpretado como un posible centro de poder local ${ }^{81}$. Conjunto de yacimientos que distan pocos kilómetros de Diego Álvaro con el que sin duda tienen una estrecha relación ${ }^{82}$. Núcleos que han deparado numerosos restos de época visigoda, y, sobre todo pizarras numerales, interpretadas como "marcas del poder de las elites sobre escenarios campesinos que no controlan directamente" 83 .

Estos datos parecen indicar una reordenación del poblamiento, a base de pequeños asentamientos asimilables a otros existentes en zonas no muy lejanas como la sierra de Guadarrama $^{84}$, la campiña del sur de Madrid ${ }^{85}$ o la Armuña salmantina ${ }^{86}$.

En todo caso, pese a la escasez en los datos con que contamos, parece existir una transformación en los modelos productivos de momentos romanos y tardorromanos, basados, principalmente, en la actividad agrícola, hacia un modelo de economía basado principalmente en la actividad ganadera -que posiblemente nunca se hubiera abandonado completamente- y la explotación de los bosques, como así parecen indicarlo ciertos análisis ${ }^{87}$.

\footnotetext{
${ }^{77}$ Barroso Cabrera, Rafael y Jorge Morín de Pablos, "La escultura de época visigoda en la provinica de Salamanca", en Salamanca: revista de estudios, 29-30 (1992), pp. 41-73; Barroso Cabrera, Rafael y Jorge Morín de Pablos, "La placa de Santibáñez de Béjar (Salamanca). Una nueva escultura de época visigoda con representación figurada", en Zephyrus, 46 (1994), pp. 369-374.

${ }^{78}$ Fuente Arrimadas, Nicolás de la, Fisiografía e Historia ... op. cit., p. 196.

${ }^{79}$ González Zymla, Herbert, "Arquitectura militar y urbanismo de frontera en Barco de Ávila", en Revista de Arqueología, 358 (2011), pp. 32-43.

${ }^{80}$ Ariño Gil, Enrique, "El yacimiento de... op. cit., pp. 251-270.

${ }^{81}$ Ariño Gil, Enrique et al., "Patrones de ocupación... op. cit., p. 123.

${ }^{82}$ Ariño Gil, Enrique, "El yacimiento de... op. cit., p. 267.

${ }^{83}$ Martín Viso, Iñaki, "Huellas del poder: pizarras y poblados campesinos en el centro de la península ibérica (siglos V-VII)", en Medievalismo, 25 (2015), p. 285.

${ }^{84}$ Hernández Sousa, José Miguel, “Arqueología del Paisaje... op. cit., pp. 74-139.

${ }^{85}$ Vigil-Escalera Guirado, Alfonso, "Granjas y aldeas altomedievales al Norte de Toledo (450-800 d.C.)", en Archivo Español de Arqueología, 80 (2007), pp. 250-251.

${ }^{86}$ Ariño Gil, Enrique et al., "De Roma al Medievo. Estructuras de hábitat y evolución del paisaje vegetal en el territorio de Salamanca" en Zephyrvs, 55 (2002), pp. 283-309.

${ }^{87}$ López Sáez, José Antonio et al., "Contribución paleoambiental al... op. cit., pp. 9-38; López-Merino, Luis et al., "2000 years of... op. cit., pp. 42-51.
} 


\subsection{Los tiempos altomedievales (siglos IX y x)}

Desde mediados del siglo VIII y hasta las primeras décadas del siglo x la zona parece haber quedado fuera de los intereses de los estados habiéndose configurado como una tierra de nadie, fuera del dominio omeya, y lejos de la escasa influencia asturleonesa ${ }^{88}$. Podría decirse que, tras la invasión musulmana, toda la zona abulense carecería de interés para ninguno de los adversarios.

Sin embargo, sabemos de la existencia de asentamientos, escasos, en la zona de estudio; situación corroborada por un lado por los registros palinológicos ${ }^{89}$ que documentan la continuidad de actividades agrícolas y ganaderas; y por la existencia de una toponimia que no era propia de esta zona ${ }^{90}$. Se trata de grupos indígenas que debieron permanecer explotando el territorio, a los que se atribuye la conservación del acervo de tradiciones orales y de la toponimia menor previa a la repoblación ${ }^{91}$. Serían grupos de residencia inestable, que ocupan preferentemente espacios "marginales" 92 poco explotados, que tratan de asegurarse derechos de propiedad a través del recurso a las tumbas excavadas en la roca ${ }^{93}$. Algunas de las cuales aparecen en lugares próximos o muy semejantes a algunas de las esculturas zoomorfas, utilizadas como marcadores de $\operatorname{pastos}^{94}$.

Los valles altos del Tormes y del Alberche, parecen ser espacios donde el impulso romano tuvo poca presencia. Zonas aprovechadas por grupos de pastores que frecuentan chozos y majadas, que explotan el medio mediante el uso del fuego, para obtener buenos pastos para el ganado $^{95}$.

Conocemos pequeñas aldeas en la Sierra de Ávila, con necrópolis de tumbas excavadas en la roca como la Dehesa de Brieva (Cillán), datadas en torno a los siglos IX y $\mathrm{X}^{96}$. Pequeños asentamientos que tras la posterior repoblación serán mayoritariamente abandonadas. Proceso que afectaría tardíamente a estas comarcas, sobre todo a las zonas más elevadas: la cabecera del Alberche a finales del siglo XIII y la del Tormes durante el XIV ${ }^{97}$. Estas zonas continuarían

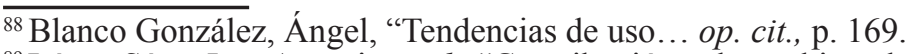

${ }^{89}$ López Sáez, Jose Antonio et al., "Contribución paleoambiental al... op. cit., pp. 9-38; López-Merino, Luis et al., "2000 years of... op. cit., pp. 42-51.

${ }^{90}$ Barrios García, Ângel, "Una tierra de... op. cit., p. 200.

${ }^{91}$ Barrios García, Ángel y Ángel Martín Expósito, "Demografía medieval: modelos de poblamiento en la Extremadura castellana a mediados del siglo XIII", en Studia historica. Historia medieval, 1 (1983), pp. 113-148; Barrios García, Ángel, Estructuras agrarias y...op. cit.

${ }_{92}^{2}$ Barrios García, Ángel, Estructuras agrarias y...op. cit., p. 109.

${ }^{93}$ Martín Viso, Iñaki, “Ancestral memories and early medieval landscapes: the case of Sierra de Ávila (Spain)”, en Early Medieval Europe, 24 (4) (2016), pp. 393-422. DOI: https://doi.org/10.1111/emed.12166

94 Álvarez-Sanchís, Jesús, "Los "verracos" del Valle del Amblés (Ávila): del análisis espacial a la interpretación socio-económicas", en Trabajos de Prehistoria, 47 (1990), p. 230. DOI: https://doi.org/10.3989/tp.1990.v47.i0.560

${ }_{95}$ Barrios García, Angel, "Una tierra de nadie... op. cit.,p. 220.

${ }^{96}$ Díaz de la Torre, Javier et al., "El despoblado de San Cristóbal o Las Henrenes (Cillán, Ávila) una aproximación al paso de la Edad Antigua a la Edad Media en tierras abulenses", en Martín Viso, Iñaki (coord.), ¿Tiempos oscuros?: territorio y sociedad en el centro de la Península Ibérica, Madrid, Silex, 2009, pp. 159-180.

${ }^{97}$ Barrios García, Ángel y Ángel Martín Expósito, "Demografía medieval: modelos... op. cit., p. 134.
} 
con un poblamiento anterior, de tipo ganadero de hábitat móvil y discontinuo, en cierto sentido marginal, que con el tiempo se plasmaría en el surgimiento de algunos de los pueblos actuales, como La Zarza y El Tremedal ${ }^{98}$.

\section{Conclusiones}

La primera conclusión debe ser a nivel metodológico, los datos aportados por el IAA se muestran como una herramienta imprescindible a la hora de plantear un estudio de poblamiento, sin embargo, no tienen la fiabilidad suficiente para extrapolar sus informaciones sin efectuar la correspondiente revisión, ese margen de error puede ser capaz de llevar a interpretaciones erróneas.

Con los datos existentes, llama la atención la inexistencia de yacimientos en el sector sur y suroeste de la zona, durante gran parte del arco cronológico estudiado, que solo parece poblarse continuamente en los siglos altomedievales. Una zona que muestra escaso poblamiento durante la II Edad del Hierro, distribuido desigualmente sobre el territorio, que va transformándose con la implantación de un nuevo modelo, impulsado tras la conquista romana, que potenció el establecimiento y explotación de las zonas bajas de los valles con suelos más productivos. Sistema que debió coexistir con el viejo modelo de explotación ganadera, de pequeños grupos móviles por el territorio.

Durante la tardoantigüedad parece apreciarse un nuevo cambio cuando, a la vez que desaparecen algunos asentamientos, los situados sobre los suelos más fértiles, se potencia, de nuevo, la explotación forestal y de pastos de altura, que, aunque nunca se habían abandonado, sí habían sufrido menor presión antrópica en los siglos anteriores.

Una zona que desde época romana ha sido marginal, situada en el límite de varias ciudades, pero alejada de todas, donde los efectos de la romanización se dejaron sentir, aunque con sus propios tiempos e impulsos. Esta situación no hará sino agravarse tras la llegada musulmana, estableciéndose una frontera física (Sistema Central), que actuará de barrera entra ambos contendientes; escenario que perdurará en la etapa medieval con la partición del territorio entre el Ducado de Béjar y el Señorío de Valdecorneja, que no se resolverá hasta 1833 con la nueva distribución administrativa de Javier Burgos.

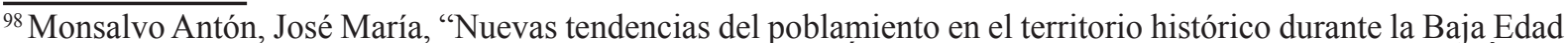
Media", en Ser Quijano, Gregorio del (ccord.), Historia de Ávila, vol. III, Edad Media (siglos XIV y XV), Ávila, Institución "Gran Duque de Alba" de la Excma. Diputación de Ávila, 2006, p. 53.
} 